TẠP CHÍ KHOA HỌC ĐẠI HỌC TÂN TRÀO

ISSN: 2354 - 1431

http://tckh.daihoctantrao.edu.vn/

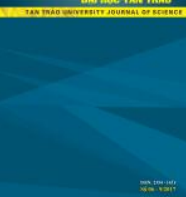

\title{
HOẠT TÍNH KHÁNG VIÊM TỪ CAO CHIÊTT LÁ CÂY VÚ BÒ (FICUS HIRTA VAHL) THU HÁI TẠI HUYỆN YÊN SON, TỈNH TUYÊN QUANG
}

\author{
Trần Thị Giáng Hương ${ }^{a *}$, Trần Đức Đại ${ }^{a}$, Chu Quỳnh Mai ${ }^{a}$ \\ ${ }^{a}$ Truờng Đại học Tân Trào \\ *Email: tranthigianghuongtytq@gmail.com
}

\section{Thông tin bài viết}

Ngày nhận bài:

$19 / 6 / 2020$

Ngày duyệt đăng:

$12 / 8 / 2020$

Tù khóa:

Ficus hirta, Moraceae, điều trị, kháng viêm, $\mathrm{IC}_{50}$.

\section{Tóm tắt}

Cây vú bò (Ficus hirta Vahl.) là một loại cây nhiệt đới được sử dụng rộng rãi trong y học cổ truyền Việt Nam và Trung Quốc có tác dụng hỗ trợ và điều trị nhiều bệnh lý như bệnh: Viêm thận, viêm gan, viêm vú, thấp khớp, ho .... Mục đích của nghiên cứu này là để chứng minh một cách khoa học khả năng chống viêm của các cao chiết lá cây vú bò. Hoạt tính kháng viêm của các cao chiết cây vú bò được đánh giá thông qua khả năng ức chế sản xuất NO trong tế bào RAW 264,7. Kết quả cho thấy cao chiết $n$-hexan; ethyl acetat, $n$-butanol có giá trị $\mathrm{IC}_{50}$ lần lượt là: 10,$46 ; 13,16 ; 98,57 \mathrm{mg} / \mathrm{ml}$. Do đó cây vú bò có tiềm năng lớn trong việc điều trị, hỗ trợ điều trị các bệnh viêm.

\section{MỞ ĐÀ̀U}

Chi Sung (Ficus L.) là một chi lớn thuộc họ Dâu tằm (Moraceae), gồm khoảng 1000 loài phân bố chủ yếu ở các vùng nhiệt đới và cận nhiệt đới [1]. Theo Phạm Hoàng Hộ có hơn 100 loài và thứ thuộc chi này có ở Việt Nam [2]. Ficus hirta Vahl., tên thường gọi là cây vú bò, vú chó hay óc chó, được dùng trong dân gian để làm thuốc bổ và chữa bệnh. Rễ cây vú bò được sử dụng để tăng cường sức khỏe và trị các chứng bệnh như viêm gan, viêm vú, ho, thấp khớp và để tăng cường tiết sữa sau khi sinh. Lá và thân được dùng dưới dạng thuốc sắc để chữa viêm thận, chữa vết thương bầm tím $[3,4]$. Trên thế giới, đã có một số nghiên cứu về thành phần hóa học của rễ [5-8] và quả [9] loài này được công bố. Nhiều hợp chất phenolic nhu flavonoid, prenylcoumarin, phenylpropanoid, coumarin cùng các alkaloid, triterpenoid ... đã được phân lập và xác định từ loài này.

\section{THỰC NGHIỆM}

\section{Nguyên liệu}

Mẫu thực vật dùng nghiên cứu là lá cây vú bò. Mẫu tươi lá cây vú bò được thu hái vào tháng 12/2019 tại Huyện Yên Sơn - Tuyên Quang. Mẫu cây được TS. Nguyễn Thị Hải, Khoa Y - Dược, Trường Đại học Tân Trào xác định tên khoa học là (Ficus hirta Vahl.) thuộc họ Dâu tằm (Moraceae).

Mẫu cây vú bò mã số (FH-12/2019) được lưu tại phòng Thực hành Dược, Trường Đại học Tân Trào.

Mẫu thực vật được thái nhỏ, sấy khô ở nhiệt độ $45^{\circ} \mathrm{C}$ trong tủ sấy, để nguội, xay nhỏ và chiết xuất với dung môi thích hợp.

\section{Dung môi, hóa chất, thiết bị}

Các dung môi, hóa chất dùng để chiết xuất, phân lập các chất: methanol, $n$-hexane, ethylacetate, dichloromethane, $n$-butanol đều đạt tiêu chuẩn phòng thí nghiệm.

Lipopolysaccharides (LPS) từ Escherichia - coli của Sigma Chemical Co. (St. Louis, MO, USA). Dulbecco's Modified Eagle's Medium (DMEM), fetal bovine serum (FBS) được cung cấp từ Life Technologies, Inc, (Gaithersburg, MD, USA). 
Sodium nitrite, sulfanilamide, N-1napthylethylenediaminedihydrochloride and dimethyl sulfanilamide (DMSO) của Sigma Chemical Co. (St. Louis, MO, USA).

Các hóa chất cần thiết khác của hãng Sigma, GiBCO, Invitrogen, Promega.

Dòng tế bào: RAW 264.7 do GS.TS. J.M.Pzzoto, Trường Đại học Hawaii và GS. Jeanette Maier, Trường Đại học Milan, Italia cung cấp.

\section{Phương pháp nghiên cứu}

\subsection{Phương pháp chiết mẫu thực vật, tạo cao chiết.}

Lá cây vú bò sau khi thu hái được tiến hành loại bỏ tạp bẩn, phơi khô trong bóng râm và xay nhỏ thành bột. Bột khô $(4 \mathrm{~kg})$ thu được được tiến hành chiết tạo cao tổng bằng ethanol $-\mathrm{H}_{2} \mathrm{O}\left(\mathrm{EtOH}: \mathrm{H}_{2} \mathrm{O}=95: 5\right)$ từ 3 đến 4 lần ở nhiệt độ phòng theo phương pháp chiết ngâm hoặc chiết trên thiết bị chiết siêu âm ở nhiệt độ 40-50 ${ }^{\circ} \mathrm{C}$. Các dịch chiết thu được được tiến hành lọc bằng giấy lọc, gộp lại và loại bỏ dung môi dưới áp suất giảm trên thiết bị cô quay chân không thu được cặn chiết EtOH $300 \mathrm{~g}$ cao tổng (Ký hiệu FL 300). Cao tổng sau đó được chiết lần lượt giữa $n$-hexane, ethyl acetate và $n$-butanol. Làm bay hơi các dung môi hữu cơ thu được các cặn chiết tương ứng là FHLH $40 \mathrm{~g}$, FHLE 50 g, FHLBu $100 \mathrm{~g}$ còn lại dịch nước.

\subsection{Phương pháp nuôi cấy tế bào in vitro}

Dòng tế bào RAW 264,7 được nuôi cấy trong môi trường DMEM với thành phần kèm theo gồm $2 \mathrm{mM}$ HEPES và $1,0 \mathrm{mM}$ sodiumpyruvate, ngoài ra bổ sung $10 \%$ fetal bovine serum - FBS (GIBCO).

Tế bào được cấy chuyển sau 3-5 ngày với tỉ lệ (1:3) và nuôi trong tủ âm $\mathrm{CO}_{2}$ ở điều kiện $37^{\circ} \mathrm{C}, 5 \% \mathrm{CO}_{2}[10]$.

3.3. Phương pháp xác định khả năng ức chế sản sinh NO của tế bào macrophage RAW 264,7

Tế bào RAW 264,7 được đưa vào 96 giếng ở nồng độ $1 \times 10^{4}$ tb/giếng và nuôi trong tủ ấm ở $37^{\circ} \mathrm{C}$ và 5 $\% \mathrm{CO}_{2}$ trong 24 giờ.

Tiếp theo, môi trường nuôi cấy được loại bỏ, thay bằng môi trường $\mathrm{DMEM}$ không có $\mathrm{FBS}$ trong 3 giờ.

Tế bào sau đó được ủ mẫu nghiên cứu ở các nồng độ khác nhau trong 2 giờ trước khi được kích thích sản sinh yếu tố NO bằng LPS $(1 \mu \mathrm{g} / \mathrm{mL})$ trong 24 giờ.

Một số giếng không được ủ mẫu mà chỉ sử dụng dung dịch pha mẫu được coi là đối chứng âm. Trong khi đối chứng dương được sử dụng là $\mathrm{N}^{\mathrm{G}}$ - Methyl-Larginine acetate (L-NMMA) (Sigma).

Nitrite $\left(\mathrm{NO}_{2}{ }^{-}\right)$, được xem là chỉ thị cho việc tạo NO, sẽ được xác định nhờ bộ Griess Reagent System (Promega Cooperation, WI, USA). Cụ thể là, $100 \mu \mathrm{l}$ môi trường nuôi tế bào (ủ mẫu) được chuyển sang đĩa 96 mới và được thêm vào $100 \mu \mathrm{l}$ Griess Reagent System (Promega Cooperation, WI, USA). Cụ thể là. $100 \mu \mathrm{l}$ môi trường nuôi tế bào (ủ mẫu) được chuyển sang đĩa 96 mới và được thêm vào $100 \mu$ l Griess reagent: $50 \mu \mathrm{l}$ của $1 \%(\mathrm{~W} / \mathrm{v})$ sulfanilamide trong 5 $\%(\mathrm{v} / \mathrm{v})$ phosphoric acid và $50 \mu \mathrm{l} 0,1 \%(\mathrm{w} / \mathrm{v}) \mathrm{N}-1$ naphthylethylenediamine dihydrochloride ph trong nước.

Hỗn hợp này được ủ tiếp ở nhiệt độ phòn trong 10 phút và hàm lượng nitrite sẽ được đo bằng máy microplate reader ở bước sóng $540 \mathrm{~nm}$. Môi trường DMEM không FBS được sử dụng như giếng trắng (blank).

Hàm lượng nitrite của từng mẫu thí nghiệm được xác định nhờ vào đường cong hàm lượng chuẩn $\mathrm{NaNO}_{2}$ và được so sánh \% với mẫu chứng âm (LPS).

Khả năng ức chế sản sinh NO của mẫu được xác định nhờ công thức:

$\%$ Úc chế $=100 \%$ - [hàm lượng $\mathrm{NO}_{\text {sample }} /$ hàm lượng $\left.\mathrm{NO}_{\text {LPS }}\right] * 100$

Phép thử được lặp lại 3 lần để đảm bảo tính chính xác. Giá trị $\mathrm{IC}_{50}$ (nồng độ ức chế $50 \%$ sự hình thành NO) sẽ được xác định nhờ vào phần mềm máy tính TableCurve 2Dv4 [11-14].

\subsection{Phép thử sinh học xác định khả năng gây} độc tế bào bằng MTT

Chất thử $(20 \mu \mathrm{l})$ được đưa vào các giếng của khay 96 giếng để có nồng độ tương tự nồng độ của thí nghiệm NO.

Sau khi điều chỉnh để có mật độ tế bào phù hợp, hút $180 \mu$ l tế bào vào các giếng của khay 96 giếng đã có chất thử. Trên cùng một đĩa thử, bố trí một số giếng để làm đối chứng không có mẫu thử chỉ có dung môi pha mẫu là DMSO $10 \%$.

Để đĩa nuôi cấy vào trong tủ ấm $\mathrm{CO}_{2}$ ở điều kiện $37{ }^{\circ} \mathrm{C}, 5 \% \mathrm{CO}_{2}$, nuôi trong 72 giờ.

Sau 72 giờ, $10 \mu \mathrm{l}$ MTT (nồng độ cuối cùng là 5 $\mathrm{mg} / \mathrm{ml}$ ) được cho vào mỗi giếng. 
Sau 4 giờ, loại bỏ môi trường, tinh thể formaran được hòa tan bằng $50 \mu \mathrm{l}$ (DMSO) $100 \%$.

Giá trị $\mathrm{OD}$ đo ở bước sóng $540 \mathrm{~nm}$ bằng máy quang phổ.

Lượng tế bào sống sót sẽ được tính theo công thức:

$\%$ ức chế $=100 \%-\left[\left(\mathrm{OD}_{\text {(chất }}\right.\right.$ thử) $-\mathrm{OD}_{\text {(chất }}$ đối chứng)/OD $\mathrm{OD}_{\text {(DMSO) }}-\mathrm{OD}_{\text {(chát đối chứng) }}$ ]

\section{Kết quả nghiên cứu}

Kết quả Bảng 1 cho thấy: ở nồng độ $100 \mu \mathrm{g} / \mathrm{ml}$, các mẫu FHLH, FHLE và FHLBu ức chế mạnh và gây chết tế bào nên giá trị ức chế NO ở nồng độ sẽ bị loại bỏ và giá trị $\mathrm{IC}_{50}$ của các mẫu này được tính từ nồng độ $20 \mu \mathrm{g} / \mathrm{ml}$.

Bảng 1. Khả năng ức chế sản sinh NO của các mẫu nghiên cứu

\begin{tabular}{|c|c|c|c|c|}
\hline \multirow{2}{*}{$\begin{array}{c}\text { Nồng độ } \\
(\mu \mathrm{g} / \mathrm{ml})\end{array}$} & FHLBu & FHLE & FHLH & L-NMMA chế sản sinh NO \\
\cline { 2 - 5 } & 50,24 & 74,65 & 65,26 & 102,54 \\
\hline 100 & 31,32 & 59,54 & 60,67 & 70,08 \\
\hline 20 & 23,42 & 31,51 & 35,65 & 35,91 \\
\hline 4 & 20,79 & 19,47 & 25,68 & 14,02 \\
\hline 0,8 & $\mathbf{9 8 , 5 7} \pm \mathbf{3 , 5 6}$ & $\mathbf{1 3 , 1 6} \pm \mathbf{0 , 5 4}$ & $\mathbf{1 0 , 4 6} \pm \mathbf{0 , 7 2}$ & $\mathbf{7 , 8 1} \pm \mathbf{0 , 7 4}$ \\
\hline
\end{tabular}

Bảng 2. Tác động của các mẫu nghiên cứu đến khả năng ức chế sự phát triển của tế bào RAW 264,7

\begin{tabular}{|c|c|c|c|c|}
\hline \multirow{2}{*}{$\begin{array}{c}\text { Nồng độ } \\
(\mu \mathrm{g} / \mathrm{ml})\end{array}$} & FHLBu & FHLE & FHLH tế bào sống sót & L-NMMA \\
\cline { 2 - 5 } & 98,69 & 27,49 & 8,58 & 95,45 \\
\hline 100 & 99,96 & 92,29 & 95,12 & 96,65 \\
\hline 20 & 94,42 & 100,33 & 97,86 & 98,43 \\
\hline 4
\end{tabular}

Kết quả trong phép thử ức chế NO các mẫu cho thấy FHLE, FHLH thể hiện hoạt tính tốt nhất với giá trị $\mathrm{IC}_{50}$ lần lượt là $10,46 \pm 0,72$ và $13,16 \pm 0,54$ $\mu \mathrm{g} / \mathrm{ml}$. Mẫu FHLBu cho thấy có hoạt tính với giá trị $\mathrm{IC}_{50} 98,57 \pm 3,56 \mu \mathrm{g} / \mathrm{ml}$. Chất đối chứng dương LNMMA hoạt động ổn định trong thí nghiệm.

\section{KẾT LUẬN}

Từ lá loài Ficus hirta thu hái tại huyện Yên Sơn, tỉnh Tuyên Quang đã chiết xuất được 4 cao chiết $n$-hexane $40 \mathrm{~g}$ (FHLH), ethylacetat $50 \mathrm{~g}$ (FHLE), $n$-butanol $100 \mathrm{~g}$ (FHLBu), cao nước (FHLN).

Thử hoạt tính kháng viêm của 3 cao chiết FHLE, FHLH, FHLBu và kết quả là: Mẫu cao chiết ethylacetat (FHLE), n-hexane (FHLH) thể hiện hoạt tính tốt với giá trị $\mathrm{IC}_{50}$ lần lượt là $10,46 \pm 0,72$ và $13,16 \pm 0,54 \mu \mathrm{g} / \mathrm{ml}$.

Mẫu cao chiết $n$-butanol (FHLBu) có hoạt tính với giá trị $\mathrm{IC}_{50} 98,57 \pm 3,56 \mu \mathrm{g} / \mathrm{ml}$.

\section{Lời cảm ơn:}

Các kết quả nghiên cứu này được hỗ trợ kinh phí từ nguồn Quỹ khoa học công nghệ trường Đại học Tân Trào; Cảm ơn phòng Nghiên cứu các hợp chất Thiên nhiên, TS. Nguyễn Thanh Tâm và các cộng sự cho phép sử dụng trang thiết bị, dụng cụ, hóa chất và tư vấn kỹ thuật; Cảm ơn TS. Nguyễn Thị Hải, Khoa Y Dược, Trường Đại học Tân Trào đã xác định tên khoa học loài vú bò (F. hirta).

\section{TÀI LIẸU THAM KHẢO:}

1. Tai-Ming Shao, Cai-Juan Zheng, Chang-Ri Han, Guang-Ying Chen, Chun-Yan Dai, Xiao-PingSong, Jin-Chao Zhang, Wen-Hao Chen. (2014). Lactones from Ficus auriculata and their effects on the proliferation function of primary mouse osteoblasts in vitro. Bioorganic \& Medicinal Chemistry Letters 24, 3952-3955.

2. Pham Hoang Ho, (2000), Vietnamese plants. Publisher: Young - Ho Chi Minh City, Vol. 2, p. 551-581. 
3. Do Tat Loi, (2004), Vietnamese medicinal plants and medicinal herbs.Publishiner: Medical, p. 915.

4. Do Si Hien, Do Thi Xuyen (2011), the flora species of the Muong ethnic group in the Hang Kia-Pa Co nature reserve, used as medicine to treat kidney disease. National Scientific Conference on Ecology and Biological Resources 4th, p. 1121 to 1123.

5. Ya J, Zhang XQ, Wang Y, Zhang QW, Chen JX, Ye WC, (2010), Two new phenolic compounds from the roots of Ficus hirta. Nat Prod Res. 24,621625.

6. Zheng RR, Wang WJ, Yang HB, Zhang QW, Zhang XQ, Ye WC, (2013), Chemical studies on roots of Ficus hirta. China Journal of Chinese Materia Medica. 38, 3696-3701.

7. Cheng J, Yi X, Wang Y, Huang X, He X, (2017), Phenolics from the roots of hairy fig (Ficus hirta Vahl.) exert prominent anti-inflammatory activity, Journal of Functional Foods. 31, 79-88.

8. Cheng J, Yi X, Chen H, Wang Y, He X. (2017), Anti-inflammatory phenylpropanoids and phenolics from Ficus hirta Vahl, Fitoterapia 121, 229-234.

9. Wan C, Chen C, Li M, Yang Y, Chen M, Chen J. (2017), Chemical constituents and antifungal activity of Ficus hirta Vahl. Fruits. Plants. 6, 44-52.

10. Lio H, Banbury L, Liang H, Wang X, Lu X, $\mathrm{Hu} \mathrm{L}, \mathrm{Wu} \mathrm{J}$ (2014), Effect of Honghua (Flos
Carthami) on nitric oxide production in RAW 264.7 cells and $\alpha$-glucosidase activity. Journal of Traditional Chinese Medicine 34(3): 362 - 368.

11. S Combet, J L Balligand, $\mathrm{N}$ Lameire, $\mathrm{E}$ Goffin, O Devuyst (2000), A Specific Method for Measurement of Nitric Oxide Synthase Enzymatic Activity in Peritoneal Biopsies. Kidney International 57(1): $332-8$

12. Po-Jung Tsai, Tzung-Hsun Tsai, Chun-Hsien $\mathrm{Yu}$, Su-Chen Ho (2007), Comparison of NOscavenging and $\mathrm{NO}$-suppressing activities of different herbal teas with those of green tea. Food Chemistry, 103(1), 181-187.

13. Natalia R. Bernardes, Marlon HeggdorneAraújo, Isabela F. J. C. Borges, Fabricio M. Almeida, Eduardo P. Amaral, Elena B. Lasunskaia, Michelle F. Muzitano, Daniela B. Oliveira (2014), Nitric oxide production, inhibitory, antioxidant and antimycobacterial activities of the fruits extract and flavonoid content of Schinus terebinthifolius. Revista Brasileira de Farmacognosia. 24 (6), 644 - 650.

14. Sarot Cheenpracha, Eun-Jung Park, Bahman Rostama, John M Pezzuto, Leng Chee Chang (2010), Inhibition of Nitric Oxide (NO) Production in Lipopolysaccharide (LPS)-activated Murine acrophage RAW 264.7 Cells by the Norsesterterpene Peroxide, Epimuqubilin A. Mar Drugs. 8(3): 429 - 437.

\section{Anti-inflammatory action from the leaf glue of vu bo (ficus hirta vahl.) Collected in Yen Son District, Tuyen Quang Province}

Tran Thi Giang Huong, Tran Duc Dai, Chu Quynh Mai

Article info

Recieved:

19/6/2020

Accepted:

$12 / 8 / 2020$

Keywords:

Ficus hirta, Moraceae, treatment, antiinflammatory, $I C_{50}$.

\section{Abstract}

Ficus hirta Vahl is a tropical plant widely used in traditional Vietnamese and Chinese medicine to relieve and treat many pathologies. It is used to treat treatment of nephritis, hepatitis, mastitis, rheumatism, cough ....The purpose of this research is to scientifically demonstrate the anti-inflammatory of the leaf glue of Ficus hirta Vahl. The anti-inflammatory action of leaf glue was evaluated by inhibition NO production in RAW cells 264.7. Results showed that leaf glue of $n$ hexane; ethyl acetate, n-butanol with IC50 values respectively: 10.46; 13,16; 98.57 $\mathrm{mg} / \mathrm{ml}$. Therefore, Ficus hirta Vahl has great potential in treating and supporting the treatment of inflammatory diseases. 